\title{
Academic representation and students as partners: Bridging the gap
}

Sharan J. Kapadia, School of Medicine, Imperial College London, United Kingdom.

Contact: sharankapadia1@gmail.com

Academic representation refers to the process by which students within higher education can provide feedback to their institutions. Generally, a small number (or network) of elected academic representatives (reps) collect feedback from their respective cohorts via surveys and polls, the results of which are presented and discussed at regular meetings between the reps and faculty members. It is not surprising that academic representation networks are implemented in medical schools worldwide; robust networks for student feedback are an excellent way to hone curricula. Although academic representation networks are essential foundations for Students as Partners, they do not in themselves constitute student partnerships (Dunne et al., 2011). There are subtle yet key differences between simply listening to the "student voice" and directly involving students as pedagogical consultants and co-producers to drive change (Dunne et al., 2011; Healey et al., 2014). Having been an academic representative at the Imperial College School of Medicine (ICSM) for 2 years running, I would like to share my perspectives and reflections on how ICSM successfully bridged the gap between academic representation, that is, between the student voice and Students as Partners.

At ICSM, the faculty effectively integrated my role as a rep with pedagogic consultancy; I was invited to participate directly in the redesign of learning environments, to be part of a COVID-19 timetabling working group, and to be a member of a communications working group. These invitations and experiences made me feel like a true partner; my role was not simply one where I gave feedback to faculty who would then make the key decisions, but that of an agent of change who could shape these decisions through active collaboration (Dunne et al., 2011; Healey et al., 2014). In this essay, I aim to explore these opportunities in detail, provide insights on how a true partnership was established, discuss potential barriers to partnership and how these may be overcome, and paint a picture of my thoughts and feelings throughout, to inspire and encourage similar experiences for reps in other institutions.

\section{LECTURE THEATRE REDESIGN}

The quality and layout of university buildings contribute significantly to the overall classroom experience and thus play a key role in higher education (Simpeh, 2014). Indeed, it has been my personal experience that the environment in which I learn has a direct bearing on my engagement, understanding, and retention. For example, I have found that in some lecture theatres, not every seat provides a good audio-visual experience, which can significantly impact my concentration. Moreover, I have always believed in making 
education accessible and fair to all. It was therefore exciting when I was invited by a member of faculty to participate in a working group for the structural redesign of an ICSM lecture theatre. The invitation was based on my role as a rep and my prior experience in curriculum review. The objectives of the task were to create a learning environment that was more conducive to group work, rather than only didactic teaching, while maintaining access throughout. I was invited to take a tour of the theatre and share my thoughts on optimal seating arrangements, corridor placement, and potential student-staff interactions, as part of a focus group comprising a senior teaching fellow in physiology, a reader in physiology, and administrative staff. Initially, I was somewhat cautious about discussing lecture theatre design with my own lecturers. Would they think I was overstepping my mark? Or perhaps they would dismiss my suggestions? However, I soon realised that the environment was supportive and friendly, and felt comfortable sharing my perspective. Discussions with the other working group members helped me see things from a different point of view; as a student, I found myself thinking largely about the impact of various design decisions on the learning environment, audio-visuals, and writing space, whereas the faculty also considered more holistic aspects such as the importance of providing accessible entrances and corridors, the value of ensuring lecture theatres are adaptable to a flipped classroom approach and group work, maintaining appropriate spacing, and keeping fire exits safely accessible. I was subsequently invited to a meeting including members of the Board, ICSM faculty, and architects who were to present blueprints for the lecture theatre. It gave me great satisfaction to know that the proverbial "loop" was being closed; I had been involved as a partner in the scoping stage and was now a partner during the planning stage. Being given the opportunity to raise my hand and offer rich, real-time suggestions that had the potential to influence plans was truly memorable and helped me develop an understanding of the overall process of lecture theatre design, including the various organisations and stages involved. It was great to see student suggestions reflected in the post-meeting email. The congruity of the situation soon dawned on me-l was actively shaping an environment where I could be taught; a true example of partnership.

\section{COVID-19 CURRICULUM REVIEW WORKING GROUP}

Given the challenges associated with COVID-19 social distancing, an urgent weekly working group was founded to adapt the curriculum and redesign room allocations, while maintaining student-centredness throughout. This group included senior faculty, teaching fellows, administrative staff, programme officers, technical support colleagues, and other key members of faculty. I was grateful to be invited by a member of faculty, owing to my role as a rep. A Year-1 rep was also invited. The feeling of partnership began from the very first invitation email. Not only was it addressed "Dear colleagues," but it also read, "I would really like you to join this group and feel your input will be extremely beneficial." The idea of togetherness was made evident from the outset. Clearly, I was not being asked to simply present feedback, but to use my knowledge and experience to drive change as part of a team. Initially, the discussions were related to timetabling and how we could stagger sessions to reduce student density. Although I was excited to begin, I was also nervous. Firstly, I felt a degree of unfamiliarity with the previous timetabling discussions despite having received an update from the team. The arrangements and plans were complex; I felt myself being rather reserved in the first meeting for fear of making an error that would embarrass me in front of my seniors. At the same time, even though faculty were incredibly supportive and friendly, I felt pressure to justify my presence. I had some initial doubts, such 
as "am I important enough to be here?," "what benefit will my presence confer?," and "how do I challenge decisions without coming across as arrogant?" Moreover, there was, of course, the perceived power dynamic between me and senior staff, especially since they had roles as assessors and lecturers. However, as the meetings progressed, I felt more at ease. Crucially, the faculty regularly invited my suggestions during the meetings and encouraged me to speak, which helped lessen the imbalance of power; I was never made to feel that I was interrupting seemingly more important team members. I was able to ask questions and challenge some of the timetabling decisions like a colleague; I was never made to feel like 'just' a student. For example, I was able to contribute to a debate on the spacing between teaching sessions. Indeed, the ability of participatory methods such as working groups to lessen the imbalance of power has been discussed in the literature (Seale, 2010). Moreover, I felt a real sense of independence when we, the reps, were given the task of developing and evaluating programmes of guided independent study (GIS), a key method of remote learning during social distancing. We were given the freedom to generate ideas and present pros and cons to the working group. I mentioned the idea of gamifying GIS to increase compliance by implementing a system that rewards completion of individual tasks, or by setting 'weekly chunks' of work. We also suggested that we should be careful when marketing GIS to students and monitoring its completion; it may be perceived as handholding or homework, which seems to contradict the idea of independent learning. Seeing some of my suggestions included in the meeting's minutes made me realise that my experience as a rep was being used to bring about real-time change in the course. Being set more research tasks such as the GIS work between meetings may have helped make our contributions even more substantial. Also, for future partnerships, offering students the chance to record the minutes would be a valuable learning opportunity. There were, of course, times when our suggestions were not taken on board-one example was when we proposed that the bulletin contain fewer images and graphics and less colour in favour of more text to reduce distraction. Faculty acknowledged our suggestion, but explained that, in fact, increasing the graphical element was thought to enable increased readership based on past feedback and meetings via enhanced aesthetic value. In such cases, I did not feel upset, primarily because the positive environment of the working group had already built my confidence, and, perhaps more importantly, because faculty communicated this in a polite and constructive manner. A particularly proud moment was when we raised the issue of staff-student communication, that is, ensuring we were communicating changes and new plans contemporaneously to students, rather than overloading them with information later, and faculty responded by allocating a new group to the cause. This moment represented all the aspects of being a student driver as opposed to simply a student voice: collaboration with staff at an institutional level, the power to bring about significant changes in resource allocation by influencing the creation of a new team, and the fact that the initial spark to act was generated by students.

\section{COMMUNICATIONS GROUP}

I was excited to work with this team to discuss ICSM's communication strategies. Our meeting included the two student reps, the MBBS Phase 1 programme officer, the Phase 1 strategic teaching fellow, and a senior teaching fellow in physiology. We focussed on two major areas: first, improving the design, content, and signposting of ICSM's newsletter, and second, communicating the changes to timetabling following COVID-19. I was again encouraged to share my views, and I closely collaborated with faculty throughout. 
This time, there were two particularly interesting aspects that highlighted the idea of partnership. Firstly, the "correct" answers were unknown to us all! It was very much a case of working together and brainstorming to gain clarity on the situation. It was one of the few times I have brainstormed with those other than my peers. The exercise once again mitigated the power dynamics inherent to such student-staff meetings; we were all working towards a common goal. Secondly, even when I presented ideas that faculty deemed less effective or novel, such as the bulletin design, I did not feel discouraged. Once again, this was because the partnership I had experienced made me confident that my ideas would be judged on their merits, not on the fact that a student had generated them. Furthermore, faculty would clearly explain their reasoning. The team concluded that there was a need to 'communicate communication' more effectively and that a restructure of the newsletter would be beneficial.

\section{FINAL THOUGHTS}

The respect I was given throughout these experiences made me feel valued.

Crucially, I believe my experiences as a rep translated well into direct pedagogical consultancy and helped me bring about real change. My prior rep experiences such as presenting to faculty at student-staff liaison group meetings (SSLGs), requesting feedback from the year group in lectures, creating social media posts to communicate outcomes to students, and generally working more closely with faculty than I otherwise would have, all built my confidence and reduced the perceived barrier to entry. It also helped greatly that I was invited to this group (which perhaps would not have happened if not for my role as rep) as it reinforced the importance of my role from the outset. My reflections were supported by the fact that my student colleague in the COVID-19 curriculum review and communication working groups was also a rep. However, I do acknowledge that this may well be more challenging for some reps than others. Firstly, considerable rep experience is needed to gain confidence and to become familiar with faculty (I was a rep for 2 years before joining the working groups). Moreover, as with other volunteer roles, being a rep is often what you make it-a rep who opts to take a more reserved approach may not feel ready to join a student partnership. Finally, I have generally considered myself to be an outgoing individual; it is possible that more introverted reps may prefer not to take on partnership roles. In general, though, I would strongly recommend that reps seek ways to get involved in participatory methods such as working groups. My suggestion would be to put yourself out there and reach out to faculty members to see if there are any groups you could join. Always remember to keep feedback actionable, thought-through, and polite. And finally, remember that all suggestions are valuable and have the power to influence your experience as a student-the maxim, "nothing about me, without me," is a motivating way to capture the essence of student partnership.

I believe that Students as Partners is as much an ethos as it is a process. As with any ethos, significant transformations require small steps and organisation-wide change. In my experience, academic representation and the student voice is an excellent foundation to build upon. Any institution with a well-established academic representation network already has the raw materials, namely the openness to invite student feedback and respect for student views to launch full-fledged student-staff partnerships. With an extra push to further attenuate power dynamics between staff and students, the establishment of working groups, and encouraging student collaboration by directly involving reps in pedagogic consultancy, we can bridge the gap between academic representation and 
Students as Partners. Indeed, when I reflect on my experience, a single word echoes in my mind: empowerment. I feel that ICSM empowered me as a rep by striving to go beyond simple feedback, committing to involve me as an agent of change, and harnessing my keenness to participate (Seale, 2010). They 'bridged the gap' and extended my role as a rep to a role as a partner. I shall savour this for a long time, and I do hope other reps get a taste of this too!

\section{ACKNOWLEDGEMENTS}

I would like to thank Dr James Moss for his support and for inviting me to join the lecture theatre redesign and curriculum review working groups, as well as all other students and staff who made these partnerships possible.

\section{NOTE ON CONTRIBUTOR}

Sharan J Kapadia is a medical student at Imperial College London, with interest in medical education and student-staff collaboration.

\section{REFERENCES}

Dunne, E., Zandstra, R., Brown, T., \& Nurser, T. (2011). Students as change agents: New ways of engaging with learning and teaching in higher education. Higher Education Academy, ESCalate (Education Subject Centre of the Higher Education Academy), University of Exeter. https://dera.ioe.ac.uk/14767/

Healey, M., Flint, A., \& Harrington, K. (2014). Engagement through partnership: Students as partners in learning and teaching in higher education. Higher Education Academy. https://www.heacademy.ac.uk/sites/default/files/resources/engagement through partnership.pdf

Seale, J. (2010). Doing student voice work in higher education: An exploration of the value of participatory methods. British Educational Research Journal, 36(6), 995-1015. https://doi.org/10.1080/01411920903342038

Simpeh, F. (2014). Comparative analysis of lecture theatre performance parameters' importance to students learning experience [Conference paper]. 3rd international Conference on Infrastructure Development in Africa, Nigeria. 